\begin{tabular}{|l|l|l|l|l|l|}
\hline J. Tek. Ling & Vol. 13 & No. 2 & Hal. 231 - 237 & Jakarta, Mei 2012 & ISSN 1441-318X \\
\hline
\end{tabular}

\title{
PERAN INJEKSI AIR SECARA ARTIFISIAL DALAM UPAYA PEMULIHAN AIR TANAH DI KABUPATEN PANDEGLANG
}

\author{
Wage Komarawidjaja, Hendra Tjahjono, Kusno Wibowo dan Samsuhadi \\ Pusat Teknologi Lingkungan - BPP Teknologi \\ wkwidjaja@scientist.com
}

\begin{abstract}
Abstrak
Kajian pemodelan pemulihan air tanah ini bertujuan untuk memperolah gambaran kemungkinan mengurangi kesulitan pasokan air dimusim kemarau dengan menginjeksikan secara artificial air hujan yang berlimpah pada musim penghujan ke dalam akuifer air tanah dangkal di Kecamatan Panimbang, Cigeulis, Munjul dan Pagelaran, Kabupaten Pandeglang, Hasil pemodelan pemulihan air tanah dangkal di empat Kecamatan tersebut memberikan gambaran bahwa : (a) program pemulihan air tanah dangkal dapat dilakukan dengan memasukkan kembali air hujan melalui sumur, (b) dari segi pemanfaatan air, pengembalian air hujan kedalam tanah dapat menjadikan ketersediaan air tanah menjadi meningkat.
\end{abstract}

Kata kunci : pemulihan air tanah, injeksi air secara artifisial.

\begin{abstract}
Recovery of groundwater modeling study aims to gain an overview possibility of reducing the dry season water supply difficulties by artificially injecting abundant rain water during the rainy season into the shallow groundwater aquifers in the District of Panimbang, Cigeulis, Munjul and Pagelaran of Pandeglang Regency, The results of modeling the recovery of shallow ground water in the four district is the idea that: (a) shallow groundwater recovery program can be done by incorporating rainwater back through wells, (b) in terms of water use, return of rainwater into the shallow groundwater aquifers make the water availability be increased.
\end{abstract}

Key words: ground water recovery, artificial water injection. 


\section{PENDAHULUAN}

\subsection{Latar Belakang}

Kabupaten Pandeglang sebagaimana disajikan pada Gambar 1, adalah salah satu Kabupaten di Provinsi Banten 1) yang akhir akhir ini sering diberitakan bahwa beberapa Kecamatan di wilayahnya terkena banjir pada saat musim penghujan ${ }^{2,3,4,5,6)}$, dan kesulitan air saa-saat musim kemarau ${ }^{7,8,9}$.

Wilayah Administrasi ini, secara geografis terletak antara $6^{\circ} 21^{\prime}-7^{0} 10^{\prime}$ Lintang Selatan dan $104^{\circ} 48^{\prime}-106^{\circ} 11^{\prime}$ Bujur Timur, yang sebagian besar wilayahnya terdiri dari dataran rendah dan dataran bergelombang. Diutara dan di selatan Kabupaten Pandeglang terdapat rangkaian pegunungan, sedangkan sungai yang mengalir di daerah administrasi Kabupaten ini diantaranya adalah Sungai Ciliman yang mengalir ke arah barat, dan Sungai Cibaliungyang mengalir ke arah selatan.

Dengan permasalahan air tersebut, perlu adanya upaya terobosan memanfaatkan sumberdaya air secara optimal dan berkelanjutan, yakni melalui upaya pengelolaan sumberdaya air secara efisien dan sesuai dengan peruntukannya ${ }^{10)}$. Hal tersebut sudah seharusnya diterapkan, mengingat air mempunyai banyak kegunaan, seperti dalam fungsi irigasi, pasokan industri, keperluan rumah tangga (minum, masak, mandi dan mencuci) dan lain-lainnya.

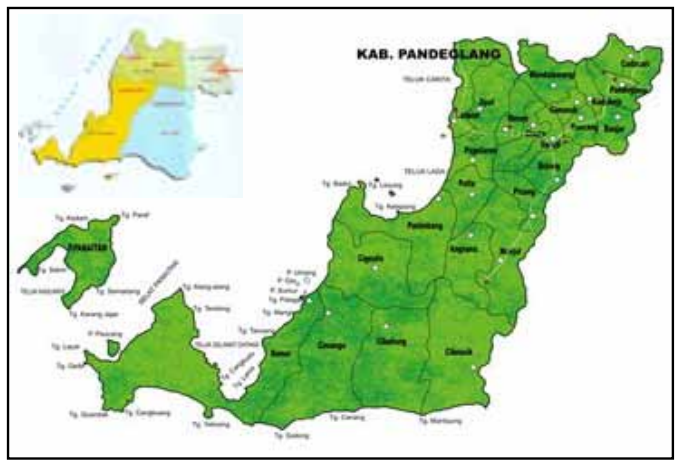

Gambar 1. Peta Administrasi Kabupaten Pandeglang, Provinsi Banten.
Namun mengingat bahwa, ketersediaan air erat kaitannya dengan faktor geografis dan iklim daerah aliran sungai, maka dalam pola pengelolaan sumberdaya air didalamnya akan selalu berkaitan dengan pola pengelolaan lahan yang memperhatikan aspek konservasi untuk melestarikan sumberdaya air.

Terjadinya musim kemarau yang mengganggu suplai air dan musim hujan mengakibatkan banjir di beberapa lokas $\mathrm{i}^{2,3,4,5,6,7)}$, merupakan suatu indikasi bahwa didaerah hulu, yang seharusnya merupakan lahan lahan peresapan air, berkurang fungsinya karena gangguan pemanfaatan hutan yang berlebihan.

Sebagaimana terungkap pada Gambar 2 bahwa, potensi air tanah di Kabupaten Pandeglang, secara hidrogeologis masuk kedalam wilayah dengan produktivitas yang bervariasi, dari produktivitas yang rendah hingga produktivitas yang tinggi.

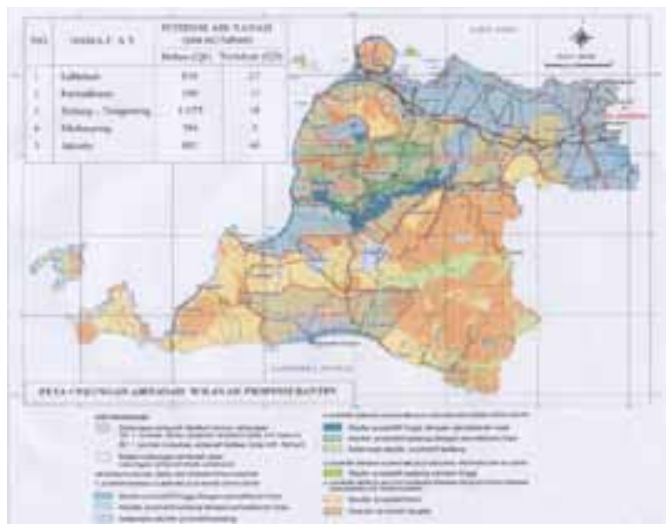

Gambar 2 : Peta Hidrogeologi Kabupatren Pandeglang dan sekitarnya

Seperti di kawasan selatan dan tengah Kabupaten Pandeglang, mempunyai akuifer dengan air tanah langka. Hanya sebagian kawasan kecil yang mempunyai akuifer dengan produktivitas sedang dan penyebaran yang terbatas, yakni didaerah pesisir barat. Akuifer disini mempunyai produktivitas sedang tapi tidak menerus. Selanjutnya untuk kawasan tengah-selatan, dikawasan ini akuifer mempunyai potensi air 
tanah sedang dan bersifat lokal, sehingga pengaruh perubahan iklim dan cuaca sangat signifikan. Sedangkan dibagian utara Kabupaten Pandeglang termasuk kawasan dengan potensi air tanah dengan produktivitas yang tinggi dan tersebar.

Salah satu kebutuhan manusia yang paling vital adalah air, karena air merupakan sumber kehidupan yang tidak dapat tergantikan oleh apa pun dan tanpa air, manusia, hewan dan tanaman tidak akan dapat hidup.

Dalam beberapa dekade terakhir, ketersediaan air menurun secara signifikan. Hal ini terjadi sebagai akibat perubahan kondisi alam yang disebabkan oleh aktifitas manusia maupun oleh perubahan iklim dunia. Alih fungsi DAS oleh manusia menyebabkan penurunan ketersediaan air dan penurunan muka air tanah. Sehubungan dengan itu, pada tahun 2007 dilaporkan bahwa telah terjadi kekeringan di Kabupaten Pandeglang, tercatat beberapa Kecamatan termasuk kedalam kategori mengalami kekeringan, seperti Kecamatan Cikedal, Pagelaran, Patia, Angsana, Cibitung, Munjul dan Cibaliung ${ }^{7)}$. Pada tahun 2011, di Kabupaten Pandeglang, laporan kekeringan terjadi di Kecamatan Panimbang seluas 50 hektar sawah, Kecamatan Pagelaran seluas 270 hektar, Kecamatan Saketi seluas 7 hektar, dan Kecamatan Labuan seluas 1 hektar ${ }^{8)}$. Dan pada awal tahun 2012, dilaporkan bahwa Kecamatan Sobang, Cigeulis, Kecamatan Panimbang dan Kecamatan Cikeusik pada akhir teriwulan pertama mengalami kekeringan ${ }^{9}$. Padahal pada awal tahun 2012, dilaporkan beberapa daerah yang mengalami kekeringan tersebut tertimpa bencana banjir $\mathrm{j}^{3,4,5,6)}$. Banjir tersebut terjadi akibat luapan Sungai Ciliman dan Cilemer yang merendam 9-11 kecamatan di Kabupaten Pandeglang, Provinsi Banten. Kecamatan tersebut meliputi :Kecamatan Patia, Pagelaran, Panimbang, Munjul, Angsana, Sobang, Sukaresmi, Cikeusik, dan Bojong ${ }^{4}$.

Dari beberapa Kecamatan yang sama dan mengalami peristiwa kekeringan dan banjir antara lain Kecamatan Pagelaran, Patia, Panimbang dan Munjul sebagaimana disajikan pada Gambar $3^{3,4,5,6,7,8,9)}$.

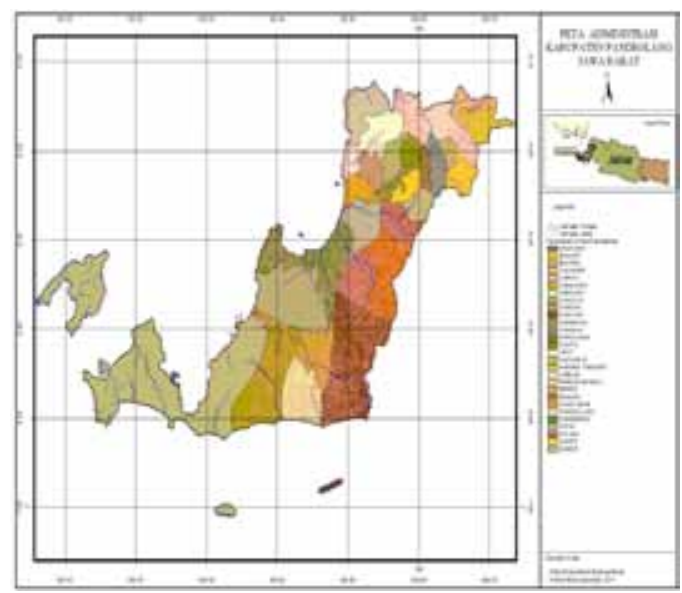

Gambar 3 : Gambaran Kawasan Terkena Kekeringan dan Banjir (Lingkaran Hitam) di Kabupatren Pandeglang.

\subsection{Tujuan.}

Adanya kondisi kesulitan air dimusim kemarau dan banjir di musim penghujan, maka upaya pemanfaatan kelebihan air dimusim hujan merupakan alternative program yang perlu dikembangkan dalam rangka pemulihan air tanah melalui peresapan air hujan secara sengaja kedalam tanah yang berpori. Namun mengingat penambahan air hujan kedalam tanah memerlukan proses yang lama, maka kajian dilakukan melalui program pemodelan, sehingga diharapkan dalam waktu yang tidak terlalu lamam dapat diperoleh gambaran kondisi air tanah sebelum dan sesudah dilakukan penambahan air secara manual melalui sumur resapan.

\section{METODOLOGI}

Kajian model injeksi artifisial air hujan dilakukan pada beberapa kecamatan, yakni Kecamatan Panimbang, Kecamatan Cigeulis, Kecamatan Munjul dan Kecamatan Pagelaran (Gambar 3 dan 4)., 
Data sekunder yang diperukan adalah peta hidrologi daerah kajian, data curah hujan Stasiun terdekat lokasi kajian, jenis tanah, porositas tanah dan konduktifitas hidrolis.

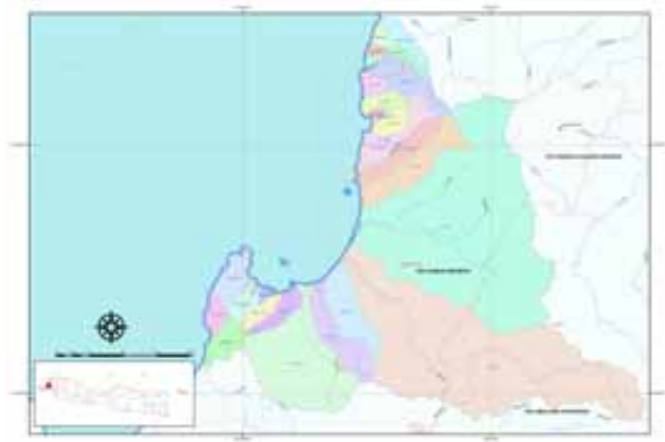

Gambar 4. Lokasi Kecamatan Panimbang, Cigeulis, Munjul dan Pagelaran serta SubDAS Cilemer dan Ciliman

Sedangkan data primer yang perlu digali dari ke-empat kecamatan adalah data kedalaman muka air tanah melalui sumur penduduk. Untuk itu, dilakukan pengamatan muka air pada sumur-sumur sampel di Kecamatan Panimbang, Kecamatan Cigeulis, Kecamatan Munjul dan Kecamatan Pagelaran.

Data data yang diperoleh akan dimasukan dalam formula model MODFLOW, suatu persamaan system air tanah, yakni persamaan diferensial parsiil ${ }^{11)}$.

\section{HASIL DAN PEMBAHASAN}

\subsection{Hasil Pemantauan Sumur Sampel}

Lokasi pemantauan sampel sumur penduduk disajikan pada Gambar 5, sedangkan data lapangan hasil pemantauan disajikan pada Tabel 1.

Data hasil pemantauan menunjukkan bahwa karakteristik air tanah memiliki kesamaan dan sesuai dengan peta hidrogeologi, karakteristik akuifer di kawasan ini memungkinkan untuk menyimpan air tanah.

Selanjutnya dari data distribusi muka air tanah dimasukkan kedalam persamaan model tersebut, sehingga dapat diperlihatkan kontur muka air tanah di wilayah kajian, sebagaimana disajikan pada Gambar 6.

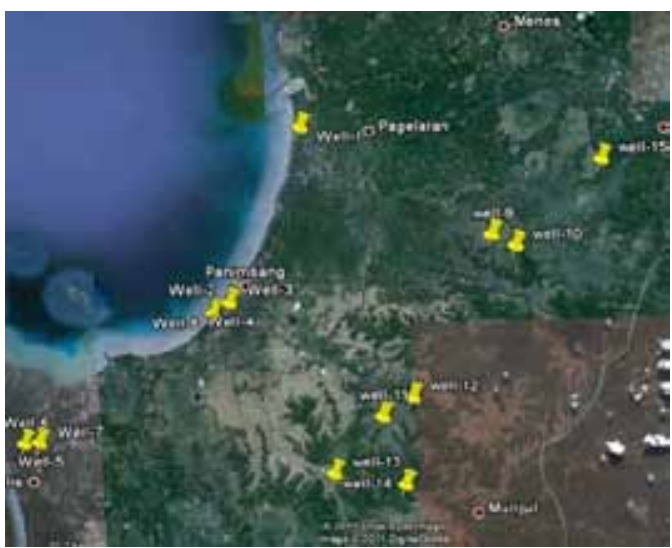

Gambar 5 : Sebaran lokasi pemantauan sumur penduduk

\begin{tabular}{|c|c|c|c|c|c|c|c|}
\hline & Kecamatan & Desa/Kelurahan & koordinat & Elev tanah & \begin{tabular}{|c|} 
Kedalaman \\
sumur
\end{tabular} & \begin{tabular}{|c|} 
Tinggi \\
muka air
\end{tabular} & Kedalaman \\
\hline \multirow[t]{2}{*}{1} & Pagelaran & Kampung Karoeng & $506^{\circ} .25,194$ & 3 & 4 & 1 & 3 \\
\hline & & & E $105^{\circ} .49,682$ & & & & \\
\hline \multirow[t]{2}{*}{2} & Panimbang & Panimbang Jaya & S $06^{\circ} .30,208$ & 5 & 4 & 2 & 2 \\
\hline & & & E $105^{\circ} .47,488$ & & & & \\
\hline \multirow[t]{2}{*}{3} & Panimbang & Panimbang Jaya & s $06^{\circ} .30,197$ & 5 & 5 & 2 & 3 \\
\hline & & & E $105^{\circ} .47,482$ & & & & \\
\hline \multirow[t]{2}{*}{4} & Panimbang & Panimbang Jaya & s $06^{\circ} .30,240$ & 6 & 3,8 & 1,5 & 2,3 \\
\hline & & & E $105^{\circ} .47,471$ & & & & \\
\hline \multirow[t]{2}{*}{5} & Cigeulis & Kampung Waru & S $06^{\circ} .34,080$ & 67 & 3,5 & 1 & 2,5 \\
\hline & & & E $105^{\circ} .41,917$ & & & & \\
\hline \multirow[t]{2}{*}{6} & Cigeulis & Kampung Waru & S $06^{\circ} .34,106$ & 83 & 5 & 1,5 & 3,5 \\
\hline & & & E $105^{\circ} .41,942$ & & & & \\
\hline \multirow[t]{2}{*}{7} & Cigeulis & Kampung Waru & S $06^{\circ} .34,124$ & 59 & 10 & 2 & 8 \\
\hline & & & E $105^{\circ} .41 .943$ & & & & \\
\hline \multirow[t]{2}{*}{8} & Panimbang & Panimbang Jaya & S $06^{\circ} .30,542$ & 4 & 5 & 2 & 3 \\
\hline & & & E $105^{\circ} .46,984$ & & & & \\
\hline
\end{tabular}

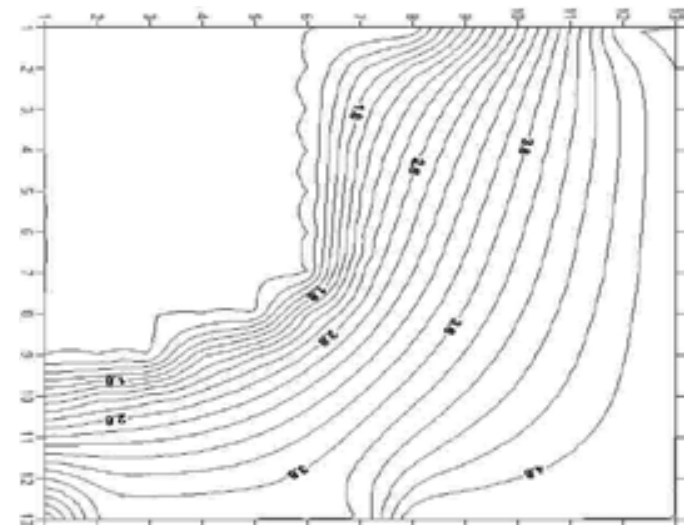

Gambar 6 : Kontur Eksisting Muka Air Tanah Dangkal.di Wilayah Kajian. 
Gambar 6 secara fisik memperlihatkan penurunan muka air tanah kearah pantai.

Selanjutnya dilakukan simulasi pemodelan air tanah dengan skenario menginjeksikan air langsung secara artifisial (manual, yakni mengalirkan air hujan langsung kedalam sumur penduduk, sehingga mencapai kedalaman air tanah dangkal. Sebagai input data adalah kedalaman air tanah (dangkal) hasil pemantauan data asumsi dan konduktifitas hidrolis dan porositas akuifer,

\subsection{Simulasi Model}

Sebagaimana telah diuraikan sebelumnya, bahwa, skenario ini dilakukan pada Kawasan yang terdiri dari empat Kecamatan (Kecamatan Panimbang, Kecamatan Cigeulis, Kecamatan Munjul dan Kecamatan Pagelaran) dengan jumlah penduduk seperti disajikan pada Tabel 2.

Tabel 2. Jumlah Penduduk Kawasan Kajian Model dan Perkiraan Penggunaan Air Tanah.

\begin{tabular}{|l|l|c|c|r|}
\hline No. & Kecamatan & $\mathbf{1}$ & $\mathbf{2}$ & \multicolumn{1}{|c|}{$\mathbf{3}$} \\
\hline 1. & Panimbang & 48.884 & 22.486 & 2.810 .75 \\
\hline 2. & Cigeulis & 33.825 & 15.559 & 1.944 .875 \\
\hline 3. & Munjul & 22.124 & 10.177 & 4.681 .42 \\
\hline 4. & Pagelaran & 33.900 & 15.594 & 7.173 .24 \\
\hline & Jumlah & 138.733 & 63.816 & 16.611 .035 \\
\hline
\end{tabular}

Ket:

$1=$ Jumlah penduduk (Jiwa)

$2=$ Pengguna Air Tanah (46\%)

$3=$ Vol. Penggunaan Air Sumur $\left(\mathrm{m}^{3} / \mathrm{hr}\right)$

Sementara sesuai dengan luas lahan kajian (kurang lebih $650 \mathrm{~km}^{3}$ ), dimana menurut Dinas Pekerjaan Umum Kabupaten Pandeglang bahwa, jumlah curah hujan di Pos Pengamatan Pandeglang menurut data tahun 2009 mencapai kurang lebih 2700 mm per tahun, maka volume air hujan yang turun dikawasan kajian adalah sekitar 1.755.000.000 $\mathrm{m}^{3}$. Jika air larian tersebut diasumsikan $80 \%$, maka air hujan yang diserap bumi (20\%) adalah sebesar $351.000 .000 \mathrm{~m}^{3}$ sebagai cadangan air tanah yang siap dimanfaatkan. Dengan tingkat peresapan air seperti diatas dan secara bersamaan juga dimanfaatkan oleh penduduk, maka kondisi air tanah dangkal membentuk kontur sebagaimana tercermin pada Gambar 6 .

Selanjutnya, melalui permodelan, peresapan air tanah buatan dapat diprogramkan dengan melakukan imbuhan air hujan langsung kedalam akuifer melalui sumur penduduk di empat kecamatan diatas, Jika diasumsikan $10 \%$ penduduk melakukan program tersebut, akan ada tambahan air sebesar 35.100.000 $\mathrm{m}^{3}$ dalam periode 1 tahun. Dengan besaran tersebut, bila pemodelan tersebut dilaksanakan maka kontur air tanah yang terjadi dapat dilihat pada Gambar 7. yang memperlihatkan kontur air sebelum aplikasi model dan Gambar 8, memperlihatkan kontur air setelah aplikasi model.

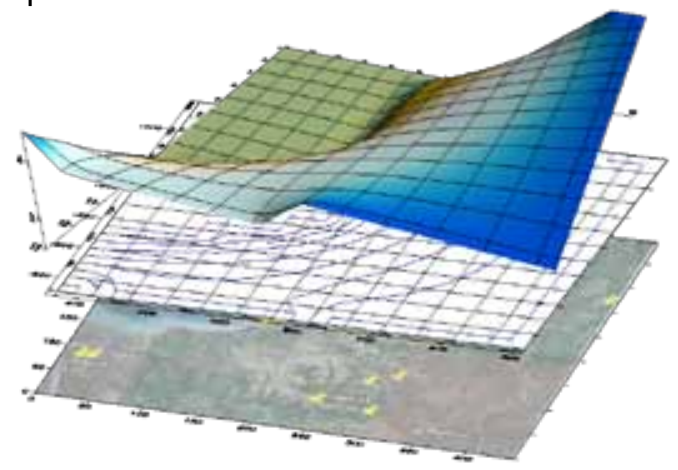

Gambar 7 : Kondisi muka air tanah sebelum Penambahan air hujan.

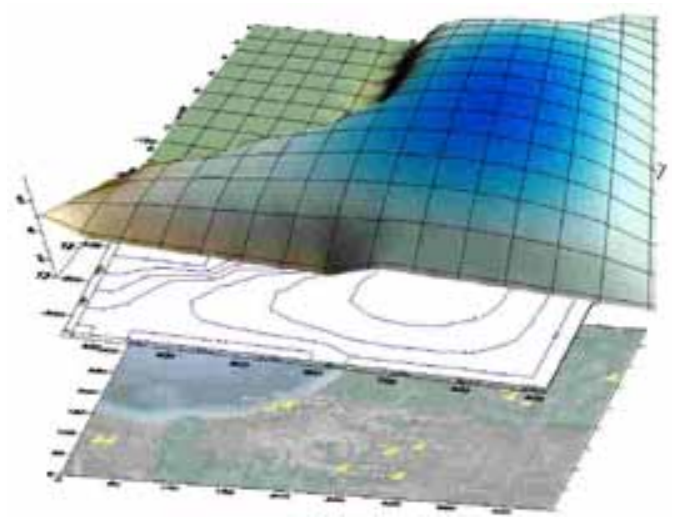

Gambar 8 : Kondisi air tanah setelah Penambahan air hujan. 
Dengan skenario 10\% dan asumsi air yang diinjekssikan tersebar secara merata keseluruh kawasan kajian model, ternyata kontur yang meningkat adalah dilokasi Kecamatan Munjul dengan ketinggian akumulasi air sekitar 7 meter sebagaimana disajikan pada Gambar 8.

Berdasarkan hasil pemodelan ini, ternyata penambahan air hujan kedalam sumur dapat meningkatkan tinggi muka air tanah dangkal. Oleh karena itu, perlu adanya gerakan masal implementasi program sumur resapan dalam suatu kawasan, sehingga upaya meresapkan air hujan kedalam akuifer dangkal dapat mengurangi resiko kesulitan air di musim kemarau.

\section{PENUTUP}

Hasil pemodelan pemulihan air tanah dangkal di Kecamatan Panimbang, Cigeulis, Munjul dan Pagelaran memberikan gambaran bahwa :

1. Program pemulihan air tanah dangkal dapat dilakukan dengan memasukkan kembali air hujan melalui sumur.

2. Dari segi pemanfaatan air, pengembalian air hujan kedalam tanah dapat menjadikan ketersediaan air tanah menjadi meningkat.

3. Syarat mutlak agar peresapan air hujan menjadi lebih lancar, harus dipilih lokasi dengan porositas tanah yang tinggi.

\section{DAFTAR PUSTAKA}

1. Anonim. 2010. Kabupaten Pandeglang Dalam Angka 2010.

2. Anonim. 2011. Banjir Pandeglang Meluas. http://www.suarapembaruan. com/home/banjir-pandeglang$\underline{\text { meluas } / 5114}$

3. Anonim. 2012. Banjir Genangi Wilayah Pandeglang. http:// www.pikiran-rakyat. com/node/173059
4. Anonim. 2012. Banjir di Pandeglang Meluas Kesembilan Kecamatan. http:// berita.liputan6.com/read/372276/ banjir-di pandeglang-meluaskesembilan-kecamatan

5. Anonim. 2012. Banjir-Di-PandeglangBerangsur-Surutkorban-DapatBantuan-Dari-Bnpb/ http://www. fesbukbantennews.com/2012/01/ banjir-di-pandeglang-berangsursurutkorban-dapat-bantuan-dari-bnpb/

6. Anonim. 2012. Banjir di Pandeglang Rendam 2.323 Rumah. http://www. tribunnews.com/2012/01/14/banjir-dipandeglang-rendam-2.323-rumah

7. Anonim. 2007. Kekeringan Di Pandeglang Makin Meluas. Anonim. 2011. Kekeringan-Ancam-WargaPandeglang-Dan-Serang-GagalPanen. http://www.republika.co.id/ berita/nasional/lingkungan/11/09/07/ $\underline{\text { Ir5avr- }}$

8. Anonim. 2012. Ribuan Hektar Sawah di Pandeglang Terancam Gagal Panen http://www.suarapembaruan.com/ home/ribuan-hektare-sawah-dipandeglang-terancam-gagalpanen/22763

9. Yanuar M., J. Purwanto Dan Sutoyo. 2009. Kebutuhan Informasi Perencanaan Sumberdaya Air Dan Keandalan Ketersediaan Air Yang Berkelanjutan Di Kawasan Perdesaan. Prosiding Seminar Nasional Himpunan Informatika Pertanian Indonesia 2009. ISBN : 978 - $979-95366-0-7$

10. McDonald, A. T.and D. Kay. 1988. Water Resources Issues \& Strategies. Themes in Resource Management. Longman Scientific \& Technical. John Wiley \& Sons. Inc. New York. 
11. Nugroho, R., P. N. Rahardjo, T. Hernaningsih, Samsuhadi, H. D. Wahjono. 2011. Efisiensi Pemanfaatan Sumberdaya Air di Kabupaten Pandeglang. . Pusat Teknologi Lingkungan BPPT.

12. Hutasoit, Lambok M. 2004. Hidrogeologi Cekungan Jakarta untuk Pengembangan Resapan Buatan. Laboratorium Simulasi Numerik Hidrogeologi. Departemen Teknik Geologi. ITB
13. Puslitbang Teknologi Sumber Daya Air Departemen Pemukiman dan Prasarana Wilayah. 2000. Studi Banjir di Wilayah Kamal - Cengkareng Kapuk. Propinsi DKI Jakarta.

14. Samsuhadi. 1990. Optimal Control Of Saltwater Intrusion. Application For The Jakarta Groundwater Basin. Master's Thesis. Humboldt State University. Arcata. California. 